\title{
Cardiovascular risk in immune-mediated inflammatory diseases
}

\author{
Carlos A. Barrera-Ochoa ${ }^{1}$, Emilio Berná-Rico², Patricia Burgos-Blasco², David Saceda-Corralo², and \\ Álvaro González-Cantero ${ }^{2,3 *}$ \\ ${ }^{1}$ Dermatology Department, Hospital General “Dr. Manuel Gea González," Mexico City, Mexico; ${ }^{2}$ Dermatology Service, Hospital Universitario Ramón \\ y Cajal, and Medicine Department, Faculty of Medicine, Universidad de Alcalá, IRYCIS, Madrid, Spain; ${ }^{3}$ Faculty of Medicine, Universidad Francisco \\ de Vitoria, Pozuelo de Alarcón, Madrid, Spain
}

\begin{abstract}
Immune-mediated inflammatory diseases (IMIDs) are a heterogeneous group of chronic diseases of unknown etiology with an inflammatory basis. They are caused by an excessive response of the immune system to various stimuli, producing chronic inflammatory lesions in different target organs with simultaneous systemic inflammation. Long-term systemic inflammation increases the risk for cardiovascular disease. Dermatologists, gastroenterologists, and rheumatologists commonly face IMIDs in their daily practice and are challenged to control the disease and provide multidisciplinary care to comorbidities and to anticipate cardiovascular outcomes. In this review, the relationship between IMIDs and cardiovascular risk is described along with the potential mechanisms that underlie these associations. Furthermore, it highlights cardiovascular disease in IMIDs patients in terms of screening and considerations for proper management.
\end{abstract}

Key words: Immune-mediated inflammatory disease. Psoriasis. Cardiovascular risk. Cardiovascular disease.

\section{Introduction}

Immune-mediated inflammatory diseases (IMIDs) are a heterogeneous group of chronic diseases of unknown etiology with an essential inflammatory basis. Despite being considered a diverse group of inflammatory diseases, they all share genetic and environmental risk factors, which explain why a patient may suffer more than two IMIDs at the same time. IMIDs usually affect young adults and are associated with a diminished quality of life and high impact on daily activities. They are caused by an excessive response of the immune system to various stimuli, producing chronic inflammatory lesions in different target organs with simultaneous systemic inflammation?.

Long-term systemic inflammation is a well-known risk factor that predisposes to cardiovascular diseases $(C V D)^{1}$. These patients have an increased risk to develop atherosclerosis with higher rates compared with a healthy population ${ }^{2}$ (Figure 1).
The pro-inflammatory profile of IMIDs is also associated with multiple comorbidities such as diabetes, obesity, and hypertension. In this review, we describe the relationship between IMIDs and cardiovascular risk and the potential mechanisms that underlie these associations (Table 1). Finally, we outline the importance of IMIDs patients regarding screening and considerations for proper management.

\section{IMIDs in dermatology}

\section{Psoriasis}

Psoriasis is a chronic inflammatory skin disease that affects $2-3 \%$ of the worldwide population ${ }^{3}$. It is characterized by an increased release of pro-inflammatory cytokines from immune-related cells with chronic activation of the innate and adaptive immune systems ${ }^{4}$. 
As a systemic inflammatory disorder, psoriasis increases the risk of developing other chronic health diseases such as metabolic syndrome, obesity, autoimmune diseases, psoriatic arthritis (PsA), depression, cancer, and non-alcoholic fatty liver disease among others and has negative effects on patients quality of life ${ }^{4}$.

Patients with severe psoriasis have an increased risk for myocardial infarction (MI) at younger ages compared to general population and have a reduced life expectancy by 4-5 years due to cardiovascular disease $^{2,5}$. Chronic pro-inflammatory profile of patients with psoriasis is associated with atherosclerosis and heart failure based on shared inflammatory pathways. Acute coronary syndrome is associated with the upregulation of interleukin (IL)-17 and Th17 cells, one of the main pathogenic cytokines found in patients with psoriasis. Furthermore, pro-inflammatory cytokines (tumor necrosis factor [TNF-a], IL-6) of patients with active psoriasis along with increased levels of markers of platelet activation (mean platelet volume, platelet-derived P-selectin, platelet-neutrophil, and lymphocyte aggregates) promote endothelial dysfunction and increase the risk for atherosclerosis. High cytokine levels of IL-17A also contribute to atherosclerotic lesion progression and plaque instability ${ }^{1,5,6}$.

Recent studies have demonstrated that patients with severe psoriasis have an increased global arterial and subcutaneous inflammation even in the aorta of patients with mild psoriasis ${ }^{7}$. Ultrasound studies of femoral arteries have shown to improve the detection of subclinical atherosclerosis in patients with moderate-to-severe psoriasis and insulin resistance and to provide a better prediction of subclinical atherosclerosis than traditional CVD risk factors ${ }^{2}$. Furthermore, traditional modifiable cardiovascular risk factors such as hypertension, diabetes, hyperlipidemia, obesity, smoking, and metabolic syndrome are highly prevalent in patients with psoriasis and further contribute to atherosclerotic development. In summary, CVD in patients with psoriasis is a combination of chronic immune system activation and pan-arterial inflammation combined with other cardiometabolic conditions ${ }^{6}$.

While the ACC/AHA suggests psoriasis as a CV risk-enhancing feature without specifying a psoriasis severity threshold ${ }^{8}$, current dermatology guidelines advocate dermatologists to inform psoriasis patients of their elevated cardiovascular risk profile and prompt referral with their primary care doctor or cardiologists. Patients with $>10 \%$ of body surface affected are candidates for systemic therapy or phototherapy. Despite the recommendation of adding a 1.5 multiplication factor to the traditional 10-year CV risk score ${ }^{9}$, our recent study showed it did not accurately captured high CVD risk psoriasis patients missing a high proportion of them with coronary plaques ${ }^{10}$.

A healthy lifestyle and optimal care in psoriasis are considered a cornerstone of strategies to reduce CVD and control disease skin severity. Weight management, control of blood pressure, exercise, smoking cessation, lipid, and glycemic control must be started in every psoriasis patient. Furthermore, targeting inflammation in psoriasis may also reduce CV risk.

Biologic treatments are now widely used in the treatment of psoriasis and some observational studies have shown to reduce $\mathrm{MI}^{11}$, and decrease surrogates of $\mathrm{CV}$ risk $^{12,13}$. A recent systematic review and meta-analysis of licensed biological therapies on imaging and biomarkers of cardiovascular disease risk in patients with psoriasis of placebo-controlled trials found that ustekinumab reduces aortic vascular inflammation and that TNF- $\alpha$ inhibitors and phototherapy reduce C-reactive protein (CRP) and IL-6 in randomized controlled trials ${ }^{14}$. Furthermore, recent reports of the use of IL-17A inhibitors have also shown a reduction in vascular stiffness and in vascular aortic inflammation ${ }^{15}$. Further randomized placebo-controlled trials are needed to determine CV prevention strategies by targeting inflammation in psoriasis patients.

\section{PsA}

PsA is an inflammatory musculoskeletal disease associated with cutaneous psoriasis. It is also considered an IMID and it is estimated that up to one-third of patients with psoriasis have PsA. PsA is also linked to cardiovascular comorbidities and is associated with higher carotid plaques. The risk for MI, stroke, or cardiovascular death is similar to patients with severe psoriasis without joint involvement ${ }^{16}$. Finally, it has been described that the number of affected dactylic digits increases cardiovascular risk including $\mathrm{MI}$, stroke, revascularization, or cardiovascular death up to $20 \%{ }^{17}$. More studies are needed to emphasize PsA and cardiovascular risk, although, current data highlights that joint involvement in patients with psoriasis also predisposes to cardiovascular risk.

\section{Hidradenitis suppurativa}

HS is a chronic, inflammatory skin disease of unknown etiology characterized by recurrent, suppurating abscesses in areas such as axillae and genital area. HS 
tends to occur in young adults with a female preponderance. It is believed that hair follicle destruction with aberrant follicular hyperkeratinization leads to local inflammation and increases the susceptibility to secondary infections and continuous stimuli for chronic inflammatory response. Patients with HS carry an increased expression of inflammatory cytokines not only in HS lesions but also systemic inflammatory load with higher concentrations of IL-1 $\beta$, IL-10, IL-17, TNF, and CRP. As with other chronic inflammatory diseases, HS has been linked to CVD, diabetes obesity, and metabolic syndrome ${ }^{18}$.

A retrospective study performed in 5964 Danish patients with HS and 29,404 individuals without HS showed a significantly increased risk of $\mathrm{Ml}$, ischemic stroke, CV-associated death, major adverse cardiovascular events, and all-cause mortality in patients with HS after adjustment for confounding factors. Furthermore, the authors showed a significantly higher cardiovascular-associated death risk in patients with HS compared to patients with severe psoriasis. Evidence showing causality or staging severity of HS and its relationship with CVD is lacking and more studies are needed to determine a direct association. In addition, heterogeneity of patients of other races/ethnicities is needed to extrapolate the results and clinicians should increase the awareness of cardiovascular risk in HS patients ${ }^{18}$. Moreover, patients with HS have a significantly higher prevalence of hypertension with odds ratios $(\mathrm{OR})$ ranging from 1.2 to $2.1^{19}$.

The use of non-invasive techniques such as carotid ultrasound may improve $\mathrm{CV}$ disease stratification in $\mathrm{HS}$ patients. A cross-sectional study performed in 60 patients with HS without a history of CV event, diabetes mellitus or chronic renal disease showed that $32.6 \%(17 / 52)$ of patients had carotid plaques in carotid ultrasound despite being categorized by Framingham Risk Score (FRS) in a low and intermediate-risk category. The authors of the latter study recommend the use of carotid ultrasound in HS patients with an intermediate risk for CVD and might be useful in low-risk patients aged 50 years and older, active smokers, or longstanding disease (>20 years) ${ }^{20}$.

Regarding cardiovascular risk screening in HS patients, a recent review suggests that dermatologists should be aware of anthropometric measurements, waist circumference measurement, blood pressure measurement, fasting lipid panel, fasting blood glucose, assessment of tobacco use, physical activity, and diet ${ }^{21}$. There are no specific intervals for screening and each patient must be evaluated based on its personalized risk.

\section{Atopic dermatitis (AD)}

$A D$ is a chronic inflammatory skin disease that affects $10-20 \%$ of children and $1-10 \%$ of adults in developed countries $^{22}$. AD has been classically linked to food allergy, allergic asthma, and allergic rhinitis. However, in the last decade, several epidemiological studies have focused on the association between $\mathrm{AD}$ and cardiovascular disease. In a recent meta-analysis of cohort studies, $A D$ was associated with an increased risk of $\mathrm{Ml}$, angina, ischemic stroke, and heart failure. Furthermore, a higher risk of CVD correlated with the severity of eczema ${ }^{23}$. Nonetheless, there was considerable between-study heterogeneity, and the association did not remain independent in the pooled analysis of cross-sectional studies. The origin of this hypothetical increase in cardiovascular events remains controversial. Patients with AD present higher odds of smoking, alcohol consumption, obesity, sedentary lifestyle, arterial hypertension, and prediabetes compared to general population ${ }^{24}$. In some studies, the association between AD and CVD became non-significant in multivariate models that adjusted for cardiovascular risk factors ${ }^{25}$. Some authors suggest that lifestyle and other cardiovascular risk factors associated with $A D$ are likely to explain the apparent increased risk of CVD found in several studies, rather than $A D$ itself. Nevertheless, moderate to severe AD displays an important profile of systemic inflammation, a well-known atherosclerotic-promotor factor. Aside from upregulation of Th2 markers, the serum proteomic signature of adults with AD shows an increment of Th22, Th17, and Th1 mediators, closely related to atherogenesis. Several atherosclerosis markers (E-selectin, CCL8, and fractalkine, among others) are also upregulated in this setting ${ }^{26}$.

On the other side, in a subset of young adult patients with moderate-to-severe $A D$, Villani et al. found significant correlations between aortic inflammation evaluated with 18-FDG PET-TC and Th2-related products in blood and skin, suggesting that the Th2 immune pathway could also play a role in the development of atherosclerosis in these patients ${ }^{27}$.

In summary, there is evidence that supports the idea that patients with AD have a higher cardiovascular risk, especially those with moderate to severe disease. Nevertheless, further studies are needed to establish this relationship and its underlying mechanisms.

\section{Alopecia areata (AA)}

AA is a chronic inflammatory disease characterized by non-scarring hair loss, with a cumulative lifetime 
incidence of approximately $2 \%$ worldwide ${ }^{28}$. Although it is not considered a traditional IMID, recent studies have demonstrated systemic inflammatory changes in AA patients. The largest study in this area remarked that these patients not only overexpress an inflammatory profile, but also have increased pro-inflammatory cytokines such as IL-6 and IL-8 contributing to the development of atherosclerosis ${ }^{29}$.

To date, few studies have evaluated the relationship between cardiovascular risk and AA. The only two published studies regarding mortality secondary to cardiovascular disease in patients with AA have reported contradictory results, with a tendency toward an increased risk of acute $\mathrm{Ml}$ over time $\mathrm{e}^{30,31}$. A possible association between metabolic syndrome and AA has also been observed, with some components of metabolic syndrome being significantly more prevalent in these patients ${ }^{32,33}$.

Taking into account the background of increased cardiovascular risk in other IMIDs, it seems reasonable to seek for a potential association to be found in AA patients. However, prospective studies are required in this field.

\section{IMIDs in gastroenterology \\ Inflammatory bowel disease (IBD)}

The gut microbiota allows immune cellular education and tolerance to an extensive number of antigens and its absence is considered to be a predisposing factor for immune-mediated disease ${ }^{34,35}$. IBD comprises two entities known as ulcerative colitis (UC) and Crohn's disease (CD). Both gastrointestinal disorders have an unknown etiology and are characterized for periods of remission, flare-ups, and relapse. IBD entities share features in matters of chronic intestinal inflammation but differ in means of genetic predisposition, environmental and clinical risk factors, endoscopic, and histological features. IBD patients have also increased systemic inflammation and multiple extraintestinal manifestations ${ }^{36}$.

There are multiple mechanisms in which IBD contributes to atherosclerotic CVD. These include local and systemic inflammation, dysbiosis, endothelial dysfunction, thrombosis, and chronic exposure to corticosteroids, which lead to insulin resistance, hypertension, and dyslipidemia. Other risk factors associated with IBD flares, persistent activity, and poor response to medical treatment such as diet, smoking, and stress are commonly shared in patients with atherosclerotic CVD ${ }^{37}$.
In terms of atherosclerotic CVD, a 2017 meta-analysis showed a multivariate-adjusted independent association between IBD and coronary heart disease (CHD) (relative risk [RR]: 1.24; 95\% confidence interval [Cl]: 1.14 to 1.36$)^{38}$. Other recent meta-analysis have confirmed an increased association between IBD and CHD (RR: $1.17 ; 95 \% \mathrm{Cl}: 1.07$ to 1.27 ), MI (RR: $1.12 ; 95 \%$ Cl: 1.05 to 1.21), and incident cerebrovascular disease (RR: $1.25 ; 95 \% \mathrm{Cl}: 1.08$ to 1.44$)^{39}$. The risk for Ml, stroke, and cardiovascular death is higher among patients with IBD flares. Longer periods of active disease in IBD are associated with increased risk for cardiovascular events and venous thromboembolic events. Furthermore, atherosclerotic CVD is increased during the $1^{\text {st }}$ year after IBD diagnosis is related to disease activity ${ }^{40,41}$.

Current recommendations include a personalized risk evaluation in these kind of patients based on disease activity and comorbidities. Until now, there are no specific guidelines for atherosclerotic CVD prevention in IBD patients and because patients are often young adults it is uncertain whether these patients should be assessed for $\mathrm{CVD}^{37}$.

\section{IMIDs in rheumatology}

\section{Rheumatoid arthritis (RA)}

$R A$ is a systemic inflammatory autoimmune disease characterized by swollen, painful, and stiffness of the joints that impair physical function and quality of life. As with other inflammatory joint disorders (IJD), RA has an increased risk for CVD compared with the general population ${ }^{42}$.

RA and unstable atherosclerotic plaques share common inflammatory mechanisms, expression of pro-inflammatory cytokines IL-1, TNF- $\alpha$, and IL- 6 . Oxidative stress in the context of inflammation contributes to the development of CVD and further induces endothelial dysfunction with subsequent atherogenesis. Anti-cyclic citrullinated peptide (ACPA) and rheumatoid factor (RF) positivity have also been associated with increased risk of ischemic heart disease and incident chronic heart failure ${ }^{43,44}$.

Since 2009, the European League Against Rheumatism (EULAR) taskforce recommended screening, identification of CVD risk factors, and risk management largely based on expert opinion. In 2016, EULAR performed a new task force to update previous recommendations. In summary, clinicians should be aware of the higher risk for CVD in patients with RA and must 
take an active role in screening and treating patients with high risk for $C V D^{42}$.

The risk of $\mathrm{MI}$ in patients with $\mathrm{RA}$ is comparable to patients with diabetes mellitus. Furthermore, the risk of $\mathrm{Ml}$ in RA is $70 \%$ higher than in the general population and has higher mortality compared with the general population ${ }^{45,46}$. Newer data from recent studies suggest that the excess risk of CVD morbidity and mortality is related to intrinsic and extrinsic factors such as carotid plaques, ACPA, RF positivity, extra-articular RA manifestations, disease duration, and hypothyroidism ${ }^{47,48}$. Nonsteroidal anti-inflammatory drugs (NSAIDs) and corticosteroids are effective treatments in lowering disease activity and inflammation in RA. While both treatment options are commonly used, they have been associated with an increased CVD risk ${ }^{49,50}$. Current updated recommendations of the EULAR for CVD risk management advocate that disease activity should be controlled optimally to the lower CVD risk in all patients with RA. Furthermore, CVD risk assessment is recommended for all patients with RA at least once every 5 years and should be reconsidered following changes in antirheumatic therapy. A healthy lifestyle, smoking cessation, and regular exercise should be recommended to all RA patients. CVD risk assessment should be performed according to national guidelines or with the SCORE CVD risk prediction model. Screening for asymptomatic atherosclerotic plaques by the use of carotid ultrasound may be considered as part of the CVD risk evaluation in patients with RA. Finally, NSAIDs and corticosteroids should be used with caution especially for patients with CVD risk factors ${ }^{42}$.

\section{Systemic lupus erythematosus (SLE)}

Lupus erythematosus (LE) is a chronic, autoimmune inflammatory disease with a wide spectrum of clinical manifestations. It is considered as the prototypical systemic autoimmune disease with significant disease burden among worldwide young adults. SLE is considered an important risk factor for increased cardiovascular morbidity and mortality ${ }^{51}$. The etiology behind increased CVD and SLE is not completely understood, it has been proposed that various mechanisms such as thromboembolisms, endothelial dysfunction, arteritis, abnormal blood flow, and accelerated atherosclerosis, contribute to accelerated cardiovascular morbidity. Furthermore, dysregulation of the innate and adaptive immune responses is also risk factors that add to the presence of CVD. Some investigations have proposed a distinct subset of pro-inflammatory neutrophils present in lupus patients, called low-density granulocytes (LDGs) to play pathogenic roles in lupus CVD by a variety of mechanisms, including their enhanced propensity to form neutrophil extracellular traps (NETs) ${ }^{52,53}$ and autoantibodies profiles may correlate to an increased risk of venous and arterial thrombosis ${ }^{54}$.

SLE patients can present at some point of their life several CVD including: coronary artery disease, myocarditis, pericarditis, endocarditis, pericarditis, cardiac arrhythmias, peripheral vascular disease, and venous thromboembolism. Some authors distinguish traditional CVD risk factors such as diabetes, hypertension, obesity, smoking, hyperlipidemia, and family history from lupus-specific risk factors. The latter are related to chronic inflammation with elevated pro-inflammatory cytokines, antiphospholipid antibodies, immune complex deposition, type 1 interferon pathway activation, lupus-related renal disease, drugs used in lupus treatment, oxidative stress, arthritis, serositis, and myocarditis among others ${ }^{55}$.

Management of CVD in SLE patients depends on the nature of the primary driving pathology. A combination of pharmacological and non-pharmacological approaches must be addressed in SLE patients with cardiovascular risk to target atherosclerosis, thrombosis, and decreases inflammation. The majority of published studies in cardiovascular manifestations in SLE focusing treatment decisions are supported by open-label studies, case series, and cross-sectional studies. Up to date, there are not established guidelines that talk about prevention in this population and decisions of treatment are extrapolated from traditional cardiovascular guidelines ${ }^{55}$.

Pharmacological management in SLE may be challenging for clinicians due to the use multiple drugs to target systemic inflammation and also, considering potential interactions and possible side effects between them. Statins are only recommended when hyperlipidemia is present despite anti-inflammatory, anti-thrombotic, immunomodulatory, and plaque stabilizing presumed effect. Due to the higher prevalence of renal disease and subsequent hypertension, reducing blood pressure is an important step to reduce cardiovascular risk. Antiplatelets and anticoagulants may be useful in SLE patients with or without antiphospholipid syndrome; however, the bleeding risk should be outweighed compared to the benefits ${ }^{55}$. Only few studies have addressed hydroxychloroquine and CVD. The majority of them suggest antimalarial have an increased protection against thrombosis and better glycemic control ${ }^{56}$. 
Table 1. Summary of IMIDs and relationship with cardiovascular disease

\begin{tabular}{|c|c|c|c|c|c|c|c|c|}
\hline & Psoriasis (PS) & $\begin{array}{l}\text { Hidradenitis suppurativa } \\
\text { (HS) }\end{array}$ & $\begin{array}{l}\text { Atopic } \\
\text { dermatitis (AD) }\end{array}$ & $\begin{array}{l}\text { Alopecia areata } \\
\text { (AA) }\end{array}$ & $\begin{array}{l}\text { Inflammatory bowel } \\
\text { disease (IBD) }\end{array}$ & $\begin{array}{l}\text { Rheumatoid } \\
\text { arthritis (RA) }\end{array}$ & $\begin{array}{l}\text { Systemic lupus } \\
\text { erychematosus (SLE) }\end{array}$ & $\begin{array}{l}\text { Ankylosing } \\
\text { spondylitis (SA) }\end{array}$ \\
\hline $\begin{array}{l}\text { Associated } \\
\text { Interleukins }\end{array}$ & $\begin{array}{l}\text { II-6, TNF- } \alpha, \text { IL22, } \\
\text { IL23 IL-17 }\end{array}$ & IL-1 $\beta$, IL-10, IL-17, TNF- $\alpha$, & IL-4, IL-13, IL-22 & IL-6, IL-8 & $\begin{array}{l}\text { II-6, INF- } \gamma \text {, } \\
\text { TNF- } \alpha, \text { IL-1, } \\
\text { IL-17 }\end{array}$ & IL-1, TNF- $\alpha$, IL-6 & $\begin{array}{l}\text { Autoantibodies, } \\
\text { IL-\$, II- } 6 \text {, INF- } \gamma \text {, } \\
\text { TNE }-\alpha, \text { IL-17 }\end{array}$ & $\begin{array}{l}\text { IL.1, IL-6, } \\
\text { TNF- } \alpha,\end{array}$ \\
\hline $\begin{array}{l}\text { Related } \\
\text { Atherosclerotic } \\
\text { plaques }\end{array}$ & $\begin{array}{l}\text { Yes } \\
\uparrow \uparrow \uparrow\end{array}$ & $\begin{array}{l}\text { Yes } \\
\uparrow \uparrow\end{array}$ & Unknown & Unknown & $\begin{array}{l}\text { Yes } \\
\uparrow \uparrow\end{array}$ & $\begin{array}{l}\text { Yes } \\
\uparrow \uparrow \uparrow\end{array}$ & $\begin{array}{l}Y e \frac{1}{3} \\
\uparrow \uparrow \frac{1}{2} \\
\frac{1}{0}\end{array}$ & $\begin{array}{l}\text { Yes } \\
\uparrow \uparrow \uparrow\end{array}$ \\
\hline $\begin{array}{l}\text { Cardiovascular } \\
\text { related events }\end{array}$ & $\begin{array}{l}\text { Myocardial } \\
\text { infarction, } \\
\text { atherosclerosis }\end{array}$ & $\begin{array}{l}\text { Myocardial infarction, } \\
\text { ischemic stroke, CV- } \\
\text { associated death. }\end{array}$ & $\begin{array}{l}\text { Myocardial } \\
\text { infarction, } \\
\text { angina, ischemic } \\
\text { stroke }\end{array}$ & $\begin{array}{l}\text { Risk for acute } \\
\text { myocardial } \\
\text { infarction }\end{array}$ & $\begin{array}{l}\text { Coronary heart } \\
\text { disease, myocardial } \\
\text { infarction, incident } \\
\text { cerebrovascular } \\
\text { disease }\end{array}$ & $\begin{array}{l}\text { Myocardial } \\
\text { infarction, } \\
\text { ischemic stroke, } \\
\text { CV-associated } \\
\text { death }\end{array}$ & $\begin{array}{l}\text { Cardiac SLE } \\
\text { manifestations + } \\
\text { increased risk } \\
\text { Myocardial } \\
\text { infarction, } \\
\text { atherosclerosisl }\end{array}$ & $\begin{array}{l}\text { Myocardial } \\
\text { infarction, } \\
\text { ischemic stroke, } \\
\text { CV-associated } \\
\text { death }\end{array}$ \\
\hline $\begin{array}{l}\text { Screening and } \\
\text { work-up for } \\
\text { cardiovascular } \\
\text { disease } \\
\text { prevention }\end{array}$ & $\begin{array}{l}\text { Weight } \\
\text { management, } \\
\text { control of blood } \\
\text { pressure, } \\
\text { exercise, smoking } \\
\text { cessation, lipid, } \\
\text { and glycemic } \\
\text { control }\end{array}$ & $\begin{array}{l}\text { Anthropometric } \\
\text { measurements, waist } \\
\text { circumference measurement, } \\
\text { blood pressure } \\
\text { measurement, fasting lipid } \\
\text { panel, fasting blood glucose, } \\
\text { smoking cessation, physical } \\
\text { activity, and diet }\end{array}$ & $\begin{array}{l}\text { No current } \\
\text { recommendations } \\
\text { available for } \\
\text { screening, } \\
\text { personalized risk } \\
\text { based upon } \\
\text { patient } \\
\text { characteristics }\end{array}$ & $\begin{array}{l}\text { No current } \\
\text { recommendations } \\
\text { available for } \\
\text { screening, } \\
\text { personalized risk } \\
\text { based upon } \\
\text { patient } \\
\text { characteristics }\end{array}$ & $\begin{array}{l}\text { Personalized risk } \\
\text { evaluation based } \\
\text { upon disease activity } \\
\text { and comorbidities. }\end{array}$ & $\begin{array}{l}\text { Healthy lifestyle, } \\
\text { smoking } \\
\text { cessation, } \\
\text { regular exercise } \\
\text { Carotid } \\
\text { ultrasound may } \\
\text { be considered }\end{array}$ & 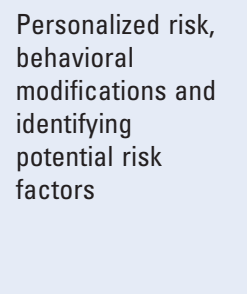 & $\begin{array}{l}\text { Control of blood } \\
\text { pressure, } \\
\text { smoking } \\
\text { cessation, and } \\
\text { optimization of } \\
\text { comorbidities }\end{array}$ \\
\hline & & & & & & & 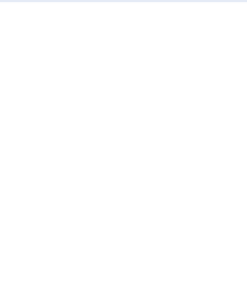 & \\
\hline
\end{tabular}




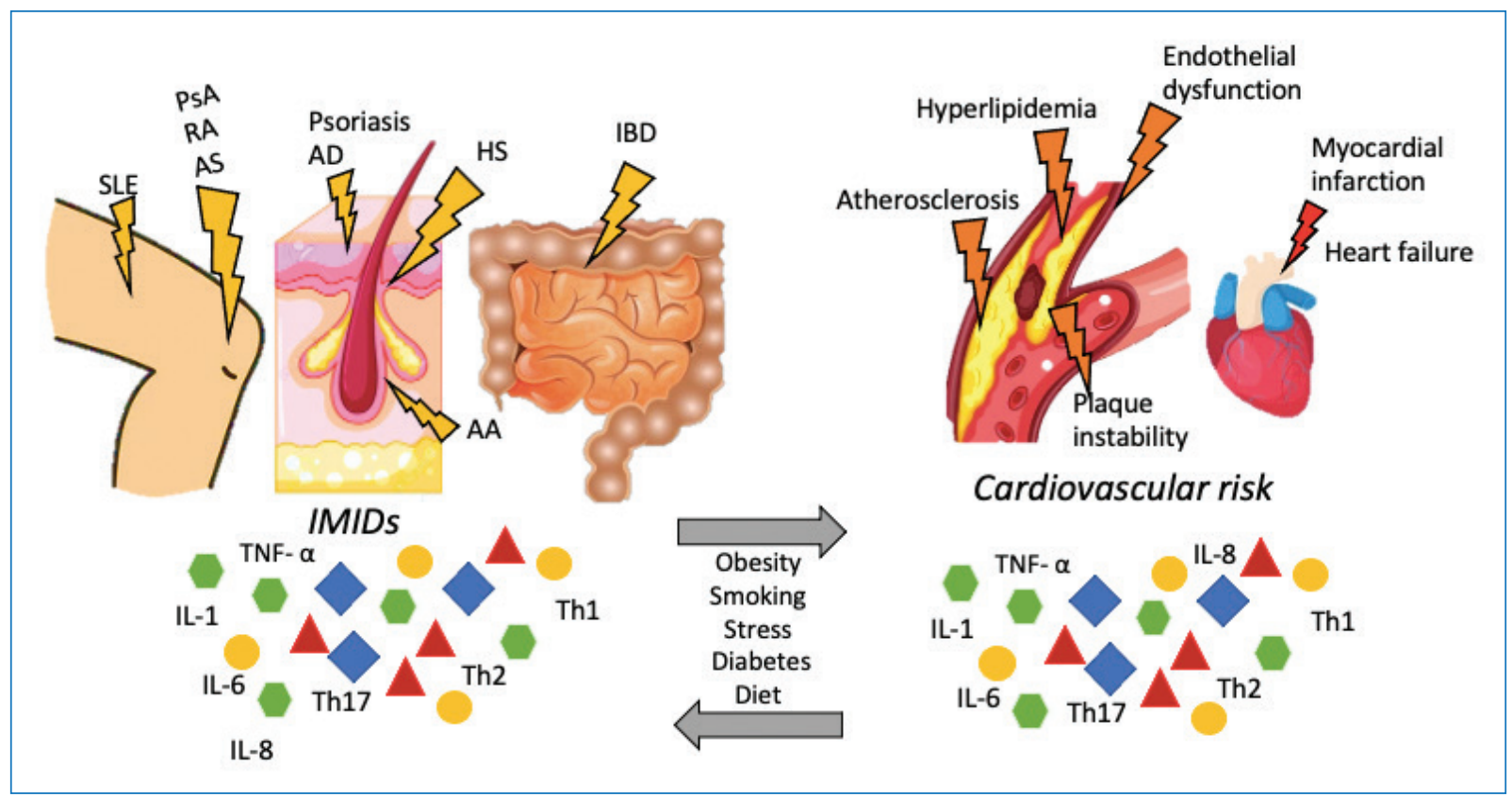

Figure 1. Schematic representation of IMIDs and cardiovascular risk. Interaction between pro-inflammatory cytokines and environmental factors that lead to an increased risk for CVD.

Both the rheumatologists and cardiologists should know the importance of assessing cardiovascular risk in SLE patients. Clinicians should be aware that behavioral modifications and identifying potential risk factors among SLE patients and might consider the use of traditional CV risk calculators so prompt detection, referral, and treatment is initiated.

\section{Ankylosing spondylitis (AS)}

AS is a chronic inflammatory disease of the axial skeleton characterized by back pain, progressive spinal stiffness, enthesopathy, peripheral arthritis, and extra-articular manifestations ${ }^{57}$

As with other IMIDs, AS is associated with increased cardiovascular morbidity and mortality compared with the general population, and its characterized by a chronic pro-inflammatory systemic profile. Risk factors for vascular death include male gender, increasing age, lower-income, chronic kidney disease, peripheral vascular disease, and the absence of NSAIDs exposure. Nevertheless, the high prevalence of cardiovascular morbidity and mortality in AS patients is related to the inflammatory pattern of the disease and because of the traditional cardiovascular risk factors ${ }^{58}$.

A recent review of cardiovascular risk factors in AS patients indicates an increased prevalence of metabolic syndrome and obesity in peripheral forms of AS. Furthermore, smoking itself, besides the traditional CV risk factor, has been associated with poorer treatment responses, increased disease activity with higher disability, and ankylosis ${ }^{59}$.

Moreover, recent a meta-analysis involving sub-clinical atherosclerosis in patients with AS showed increased intima-media thickness and pulse wave velocity (PWV) and decreased flow-mediated dilatation. The authors established that patients with AS are at higher risk of sub-clinical atherosclerosis and imply that early screening must be taken into account when evaluating AS patients ${ }^{60}$.

Anti-TNF drugs are the most used treatment in patients with AS. The main purpose of anti-TNF drugs is to reduce inflammation and it would be reasonable to relate it may decrease the risk for CVD. Some studies have found a reduction of sub-clinical atherosclerosis in SA patients treated with anti-TNF drugs ${ }^{61,62}$ despite an increase of triglycerides, high-density lipid cholesterol, and low-density cholesterol may be attributable secondary to inflammation control ${ }^{58}$.

In respect of prevention strategies, AS patients must be screened for traditional CV factors with a CV risk stratification score such as the FRS or the Systematic Coronary Risk Evaluation algorithm. As with RA patients, 2015/2016 EULAR recommendations include 
the identification and management of traditional risk factors, regular check of blood pressure, smoking cessation, and optimization of comorbidities ${ }^{42}$.

\section{Conclusions}

IMIDs represent a high burden of disease in young adults not only in matters of their disease but also with reference to an increased cardiovascular risk and a higher prevalence of CVD. It is important to note that proper control of inflammation in IMIDs is fundamental to achieve better outcomes in quality of life, management of comorbidities, and prevent further CVD.

Early screening for traditional cardiovascular risk factors in IMIDs and the use of risk calculators and algorithms as well as non-invasive studies represent an opportunity to dermatologists, gastroenterologists, rheumatologists for a prompt referral to cardiologists, and allowing patients the opportunity to improve their quality of life.

It is essential to increase the awareness of IMIDs and their relevance to all health-care professionals so multidisciplinary care approaches are installed and better outcomes can be assured.

\section{Funding}

No funding to disclose.

\section{Conflicts of interest}

Dr. Gonzalez-Cantero has served as a consultant for AbbVie, Janssen, Novartis Pharmaceutical, Almirall, Celgene, and LEO Pharma receiving grants and/or other payments, outside the submitted work. The others authors have no conflict of interest to disclose.

\section{Ethical disclosures}

Protection of human and animal subjects. The authors declare that no experiments were performed on humans or animals for this study.

Confidentiality of data. The authors declare that no patient data appear in this article.

Right to privacy and informed consent. The authors declare that no patient data appear in this article.

\section{References}

1. Davidovici BB, Sattar N, Jörg PC, Puig L, Emery P, Barker JN, et al. Psoriasis and systemic inflammatory diseases: potential mechanistic links between skin disease and co-morbid conditions. J Invest Dermatol. 2010;130:1785-96.
2. Gonzalez-Cantero A, Gonzalez-Cantero J, Sanchez-Moya Al, Perez-Hortet C, Arias-Santiago S, Schoendorff-Ortega C, et al. Subclinical atherosclerosis in psoriasis. Usefulness of femoral artery ultrasound for the diagnosis, and analysis of its relationship with insulin resistance. PLoS One. 2019;14:e0211808.

3. Boehncke WH, Schön MP. Psoriasis. Lancet. 2015;386:983-94.

4. Greb JE, Goldminz AM, Elder JT, Lebwohl MG, Gladman DD, Wu JJ, et al. Psoriasis. Nat Rev Dis Prim. 2016;2:16082.

5. Korman NJ. Management of psoriasis as a systemic disease: what is the evidence? Br J Dermatol. 2020;182:840-8

6. Garshick MS, Ward NL, Krueger JG, Berger JS. Cardiovascular risk in patients with psoriasis. J Am Coll Cardiol. 2021;77:1670-80.

7. Hjuler KF, Gormsen LC, Vendelbo MH, Egeberg A, Nielsen J, Iversen L. Increased global arterial and subcutaneous adipose tissue inflammation in patients with moderate-to-severe psoriasis. $\mathrm{Br} J$ Dermatol. 2017; 176:732-40.

8. Arnett DK, Blumenthal RS, Albert MA, Buroker AB, Goldberger ZD, Hahn EJ, et al. 2019 ACC/AHA guideline on the primary prevention of cardiovascular disease: executive summary. J Am Coll Cardiol. 2019;74:1376-414.

9. Elmets CA, Leonardi CL, Davis DM, Gelfand JM, Lichten J, Mehta NN, et al. Joint AAD-NPF guidelines of care for the management and treatment of psoriasis with awareness and attention to comorbidities. J Am Acad Dermatol. 2019;80:1073-113.

10. Gonzalez-Cantero A, Reddy AS, Dey AK, Gonzalez-Cantero J, Munger $\mathrm{E}$, Rodante $\mathrm{J}$, et al. Underperformance of clinical risk scores in identifying imaging-based high cardiovascular risk in psoriasis: results from two observational cohorts. Eur J Prev Cardiol. 2020;2020:zwaa033.

11. Wu JJ, Poon KYT Channual JC, Shen AY. Association between tumor necrosis factor inhibitor therapy and myocardial infarction risk in patients with psoriasis. Arch Dermatol. 2012;148:1244.

12. Sanz-Martínez MT, Moga E, Martínez MA, Atenza CZ, Vidal S, Juárez C, et al. High levels of platelet-lymphocyte complexes in patients with psoriasis are associated with a better response to anti-TNF- $\alpha$ therapy. $\mathrm{J}$ Invest Dermatol. 2020;140:1176-83.

13. Elnabawi YA, Dey AK, Goyal A, Groenendyk JW, Chung JH, Belur AD, et al. Coronary artery plaque characteristics and treatment with biologic therapy in severe psoriasis: results from a prospective observational study. Cardiovasc Res. 2019;115:721-8.

14. González-Cantero A, Ortega-Quijano D, Álvarez-Díaz N, Ballester MA, Jimenez-Gomez N, Jaen P, et al. Impact of biological agents on imaging and biomarkers of cardiovascular disease in patients with psoriasis: a systematic review and meta-analysis of randomized placebo-controlled trials. J Invest Dermatol. 2021;2021:24.

15. Makavos G, Ikonomidis I, Andreadou I, Varoudi M, Kapniari I, Loukeri E, et al. Effects of interleukin 17A inhibition on myocardial deformation and vascular function in psoriasis. Can J Cardiol. 2020;36:100-11.

16. Ahlehoff $\mathrm{O}$, Gislason $\mathrm{GH}$, Charlot $\mathrm{M}$, Jørgensen $\mathrm{CH}$, Lindhardsen J, Olesen $\mathrm{JB}$, et al. Psoriasis is associated with clinically significant cardiovascular risk: a Danish nationwide cohort study. J Intern Med. 2011;270:147-57.

17. Eder L, Gladman DD. Atherosclerosis in psoriatic disease: latest evidence and clinical implications. Ther Adv Musculoskelet Dis. 2015;7:187-95.

18. Egeberg A, Gislason GH, Hansen PR. Risk of major adverse cardiovascular events and all-cause mortality in patients with hidradenitis suppurativa. JAMA Dermatol. 2016:152:429.

19. Lee JH, Kwon HS, Jung HM, Kim GM, Bae JM. Prevalence and comorbidities associated with hidradenitis suppurativa in Korea: a nationwide population-based study. J Eur Acad Dermatol Venereol. 2018;32:1784-90.

20. González-López MA, Lacalle M, Mata C, López-Escobar M, Corrales A, López-Mejías R, et al. Carotid ultrasound is useful for the cardiovascular risk stratification in patients with hidradenitis suppurativa. PLoS One. 2018:13:e0190568.

21. Garg A, Malviya N, Strunk A, Wright S, Alavi A, Alhusayen R, et al. Comorbidity screening in hidradenitis suppurativa: evidence-based recommendations from the US and Canadian hidradenitis suppurativa foundations. J Am Acad Dermatol. 2021;2021:213-9.

22. Nutten S. Atopic dermatitis: Global epidemiology and risk factors. Ann Nutr Metab. 2015;66:8-16.

23. Ascott A, Mulick A, Yu AM, Prieto-Merino D, Schmidt M, Abuabara K, et al. Atopic eczema and major cardiovascular outcomes: a systematic review and meta-analysis of population-based studies. J Allergy Clin Immunol. 2019;143:1821-9.

24. Silverberg JI, Greenland P. Eczema and cardiovascular risk factors in 2 US adult population studies. J Allergy Clin Immunol. 2015;135:721-8.e6.

25. Andersen YM, Egeberg A, Gislason GH, Hansen PR, Skov L, Thyssen JP. Risk of myocardial infarction, ischemic stroke, and cardiovascular death in patients with atopic dermatitis. J Allergy Clin Immunol. 2016;138:310-2.e3.

26. Brunner PM, Suárez-Fariñas M, He H, Malik K, Wen HC, Gonzalez J, et al. The atopic dermatitis blood signature is characterized by increases in inflammatory and cardiovascular risk proteins. Sci Rep. 2017;7:8707.

27. Villani AP, Pavel AB, Wu J, Fernandes M, Maari C, Saint-Cyr Proulx E et al. Vascular inflammation in moderate-to-severe atopic dermatitis is associated with enhanced Th2 response. Allergy. 2021;2021:14859. 
28. Miteva M, Villasante A. Epidemiology and burden of alopecia areata: a systematic review. Clin Cosmet Investig Dermatol. 2015;8:397-403

29. Glickman JW, Dubin C, Renert-Yuval Y, Dahabreh D, Kimmel GW, Auyeung $\mathrm{K}$, et al. Cross-sectional study of blood biomarkers of patients with moderate to severe alopecia areata reveals systemic immune and cardiovascular biomarker dysregulation. J Am Acad Dermatol. 2021;84:370-80.

30. Shin JW, Kang T, Lee JS, Kang MJ, Huh CH, Kim MS, et al. Time-dependent risk of acute myocardial infarction in patients with alopecia areata in Korea. JAMA Dermatol. 2020;156:763.

31. Huang KP, Joyce CJ, Topaz M, Guo Y, Mostaghimi A. Cardiovascular risk in patients with alopecia areata (AA): a propensity-matched retrospective analysis. J Am Acad Dermatol. 2016;75:151-4.

32. Abdollahimajd F, Niknezhad N, Bahreini N, Younespour S, Namazi N Metabolic syndrome in patients with alopecia areata: A case-control study. Dermatol Ther. 2021;34:e14979.

33. Nasimi M, Shakoei S, Abedini R, Ghandi N, Faghihi Z. A cross-sectiona study of metabolic syndrome in patients with alopecia areata. Indian Dermatol Venereol Leprol. 2021;87:427.

34. Okada H, Kuhn C, Feillet $\mathrm{H}$, Bach JF. The "hygiene hypothesis" for autoimmune and allergic diseases: an update. Clin Exp Immunol. 2010;160:1-9.

35. Collado MC, Rautava S, Isolauri E, Salminen S. Gut microbiota: a source of novel tools to reduce the risk of human disease? Pediatr Res. 2015;77:182-8.

36. Flynn S, Eisenstein S. Inflammatory bowel disease presentation and diagnosis. Surg Clin North Am. 2019;99:1051-62.

37. Cainzos-Achirica M, Glassner K, Zawahir HS, Dey AK, Agrawal T, Quigley EM, et al. Inflammatory bowel disease and atherosclerotic cardiovascular disease. J Am Coll Cardiol. 2020;76:2895-905.

38. Feng W, Chen G, Cai D, Zhao S, Cheng J, Shen H. Inflammatory bowe disease and risk of ischemic heart disease: an updated meta-analysis of cohort studies, J Am Heart Assoc. 2017;6:e005892.

39. Sun $\mathrm{HH}$, Tian F. Inflammatory bowel disease and cardiovascular disease incidence and mortality: A meta-analysis. Eur $\mathrm{J}$ Prev Cardiol. 2018;25:1623-31.

40. Kristensen SL, Ahlehoff O, Lindhardsen J, Erichsen R, Jensen GV, Torp-Pedersen $\mathrm{C}$, et al. Disease activity in inflammatory bowel disease is associated with increased risk of myocardial infarction, stroke and cardiovascular death a danish nationwide cohort study. PLoS One. 2013;8:e56944

41. Card TR, Zittan E, Nguyen GC, Grainge MJ. Disease activity in inflammatory bowel disease is associated with arterial vascular disease. Inflamm Bowel Dis. 2021;27:629-38.

42. Agca R, Heslinga SC, Rollefstad S, Heslinga M, Mclnnes IB, Peters MJ et al. EULAR recommendations for cardiovascular disease risk management in patients with rheumatoid arthritis and other forms of inflammatory joint disorders: 2015/2016 update. Ann Rheum Dis. 2017;76:17-28.

43. Navarro-Millán I, Yang S, DuVall SL, Chen L, Baddley J, Cannon GW, et al. Association of hyperlipidaemia, inflammation and serological status and coronary heart disease among patients with rheumatoid arthritis: data from the national veterans health administration. Ann Rheum Dis. 2016;75:341-7.

44. López-Longo FJ, Oliver-Miñarro D, de la Torre I, González-Díaz de Rábago $\mathrm{E}$, Sánchez-Ramón S, Rodríguez-Mahou M, et al. Association between anti-cyclic citrullinated peptide antibodies and ischemic heart disease in patients with rheumatoid arthritis. Arthritis Rheum. 2009:61:419-24.

45. Lindhardsen J, Ahlehoff $\mathrm{O}$, Gislason $\mathrm{GH}$, Madsen OR, Olesen JB, Torp-Pedersen $\mathrm{C}$, et al. The risk of myocardial infarction in rheumatoid arthritis and diabetes mellitus: a Danish nationwide cohort study. Ann Rheum Dis, 2011:70:929-34.
46. Dadoun S, Zeboulon-Ktorza N, Combescure C, Elhai M, Rozenberg S, Gossec L, et al. Mortality in rheumatoid arthritis over the last fifty years: systematic review and meta-analysis. Joint Bone Spine. 2013;80:29-33.

47. Liao KP, Solomon DH. Traditional cardiovascular risk factors, inflammation and cardiovascular risk in rheumatoid arthritis. Rheumatology. 2013;52:45-52.

48. Solomon DH, Kremer J, Curtis JR, Hochberg MC, Reed G, Tsao P, et al. Explaining the cardiovascular risk associated with rheumatoid arthritis: traditional risk factors versus markers of rheumatoid arthritis severity. Ann Rheum Dis. 2010;69:1920-5.

49. Lindhardsen J, Gislason GH, Jacobsen S, Ahlehoff O, Olsen AM, Madsen $\mathrm{R}$, et al. Non-steroidal anti-inflammatory drugs and risk of cardiovascular disease in patients with rheumatoid arthritis: a nationwide cohort study. Ann Rheum Dis. 2014;73:1515-21.

50. del Rincón I, Battafarano DF, Restrepo JF, Erikson JM, Escalante A Glucocorticoid dose thresholds associated with all-cause and cardiovascular mortality in rheumatoid arthritis. Arthritis Rheumatol. 2014; 66:264-72.

51. Amaya-Amaya J, Sarmiento-Monroy JC, Caro-Moreno J, Molano-González N, Mantilla RD, Rojas-Villarraga A, et al. Cardiovascular disease in Latin American patients with systemic lupus erythematosus: a cross-sectional study and a systematic review. Autoimmune Dis. 2013;2013:794383.

52. Knight JS, Kaplan MJ. Lupus neutrophils. Curr Opin Rheumatol. 2012;24:441-50.

53. Ylä-Herttuala S, Palinski W, Butler SW, Picard S, Steinberg D, Witztum $\mathrm{JL}$. Rabbit and human atherosclerotic lesions contain IgG that recognizes epitopes of oxidized LDL. Arterioscler Thromb A J Vasc Biol. 1994 14:32-40

54. Miyakis S, Lockshin MD, Atsumi T, Branch DW, Brey RL, Cervera R, et al. International consensus statement on an update of the classification criteria for definite antiphospholipid syndrome (APS). J Thromb Haemost. 2006;4:295-306

55. Piranavan P, Perl A. Management of cardiovascular disease in patients with systemic lupus erythematosus. Expert Opin Pharmacother. 2020;21:1617-28.

56. Ruiz-Irastorza G, Ramos-Casals M, Brito-Zeron P, Khamashta MA. Clinical efficacy and side effects of antimalarials in systemic lupus erythematosus: a systematic review. Ann Rheum Dis. 2010;69:20-8.

57. Sieper J, Braun J, Rudwaleit M, Boonen A, Zink A. Ankylosing spondylitis: an overview. Ann Rheum Dis. 2002:61 Suppl 3:8iii-18.

58. Atzeni F, Nucera V, Galloway J, Zoltán S, Nurmohamed M. Cardiovascular risk in ankylosing spondylitis and the effect of anti-TNF drugs: a narrative review. Exp Opin Biol Ther. 2020:20:517-24.

59. Jones GT, Ratz T, Dean LE, Macfarlane GJ, Atzeni F. Disease severity in never smokers, ex-smokers, and current smokers with axial spondyloarthritis: results from the scotland registry for ankylosing spondylitis. Arthritis Care Res (Hoboken) 2017;69:1407-13

60. Bai R, Zhang Y, Liu W, Ma C, Chen X, Yang J, et al. The relationship of ankylosing spondylitis and subclinical atherosclerosis: A systemic review and meta-analysis. Angiology. 2019;70:492-500

61. van Sijl AM, van Eijk IC, Peters MJL, Serné EH, van der Horst-Bruinsma IE, Smulders YM, et al. Tumour necrosis factor blocking agents and progression of subclinical atherosclerosis in patients with ankylosing spondylitis. Ann Rheum Dis. 2015;74:119-23.

62. Zardi EM, Pipita ME, Giorgi C, Lichinchi D, Zardi DM, Afeltra A. Differences in carotid atherosclerosis between patients with ankylosing spondylitis treated with tumor necrosis factor- $\alpha$ antagonists and healthy matched controls. Medicine (Baltimore). 2018;97:e11250. 